Article

\title{
Development of Surface-Modified Polyacrylonitrile Fibers and Their Selective Sorption Behavior of Precious Metals
}

\author{
Areum Lim ${ }^{1}$, Myung-Hee Song ${ }^{2}$, Chul-Woong Cho ${ }^{2, *}$ and Yeoung-Sang Yun ${ }^{1,2, *}$ \\ 1 Department of Bioprocess Engineering, Chonbuk National University, Jeonju 561-756, Korea; \\ vhzkfltn@gmail.com \\ 2 School of Chemical Engineering, Chonbuk National University, Jeonju 561-756, Korea; bsbsmh@jbnu.ac.kr \\ * Correspondence: choicejoe@jbnu.ac.kr (C.-W.C.); ysyun@jbnu.ac.kr (Y.-S.Y.); \\ Tel.: +82-63-270-2308 (C.-W.C. \& Y.-S.Y.); Fax: +82-63-270-2306 (C.-W.C. \& Y.-S.Y.)
}

Academic Editor: Mohamed Khayet

Received: 6 November 2016; Accepted: 17 November 2016; Published: 25 November 2016

\begin{abstract}
The purpose of this study was to design a powerful fibrous sorbent for recovering precious metals such as $\mathrm{Pd}(\mathrm{II})$ and $\mathrm{Pt}(\mathrm{IV})$, and moreover for identifying its selectivity toward $\mathrm{Pd}(\mathrm{II})$ or $\mathrm{Pt}(\mathrm{IV})$ from a binary metal solution. For the development of the sorbent, polyacrylonitrile (PAN) was selected as a model textile because its morphological property (i.e., thin fiber form) is suitable for fast adsorption processes, and a high amount of PAN has been discharged from industrial textile factories. The PAN fiber was prepared by spinning a PAN-dimethylsulfoxide mixture into distilled water, and then its surface was activated through amidoximation so that the fiber surface could possess binding sites for Pd(II) and Pt(IV). Afterwards, by Fourier-transform infrared (FT-IR) and scanning electron microscopy (SEM) analyses, it was confirmed that the amidoximation reaction successfully occurred. The surface-activated fiber, designated as PAN-oxime fiber, was used to adsorb and recover precious metals. In the experiment results, it was clearly observed that adsorption capacity of PAN-oxime fiber was significantly enhanced compared to the raw material form. Actually, the raw material does not have sorption capacity for the metals. In a comparison study with commercial sorbent (Amberjet ${ }^{\mathrm{TM}} 4200$ ), it was found that adsorption capacity of PAN-oxime was rather lower than that of Amberjet ${ }^{\mathrm{TM}} 4200$, however, in the aspects of sorption kinetics and metal selectivity, the new sorbent has much faster and better selectivity.
\end{abstract}

Keywords: polyacrylonitrile; precious metals; adsorption; recovery; selectivity

\section{Introduction}

Platinum group metals (such as $\mathrm{Pd}, \mathrm{Pt}, \mathrm{Au}, \mathrm{Ru}, \mathrm{Ir}$, and $\mathrm{Os}$ ) can be naturally found at very low quantities in the earth's crust, and they are regarded as precious metals. In general, plenty of the precious metals have been used as catalytic elements by diverse industrial fields like automobile, petrochemical, and electronic components industries, although their availabilities are limited and they are expensive. After use, liquid or solid wastes, including a large amount of the precious metals, have been discharged from many industries. Such release of the metals without recovery is unprofitable for companies, and the released chemicals can play roles as toxicants in environments [1]. Therefore, recovery processes for precious metals from the industrial wastes should be an important practice.

If recovery processes for metals are methodologically established, the waste solution containing precious metals can be regarded as secondary sources. Indeed, many researchers reported that some precious metals could be recovered using various techniques such as solvent extraction $[2,3]$, chemical precipitation [4,5], ion exchange system [6,7], and chelation [8]. However, there were several drawbacks to these techniques, such as poor selectivity, difficult stripping, low recovery efficiencies 
or high capital costs for establishing the processes, and disposal costs for chemical wastes used for recovery $[9,10]$. Therefore, the use of these techniques should be limited [11]. To overcome the drawbacks, adsorption-based recovery of precious metals from wastewater is a promising process, because the process is effective and economical for treating aqueous effluents, even at low concentrations of metal. However, the efficiency of the process is strongly dependent on the employed sorbent.

Among several sorbents' types (e.g., bead, capsule, fiber, etc.), fibrous-type ones have been attractive because they have large surface areas, implying that plenty of functional groups can be potentially activated by chemical modifications. As a result, these characteristics can contribute to higher adsorption capacities and faster adsorption rates [12]. Until now, many types of fibrous agents-for example, activated carbon fiber [13], cotton fiber [14], glass fiber [15], and polymer fiber [16]—have been presented.

Currently, polyacrylonitrile (PAN), with a molecular formula of $\left[\mathrm{C}_{3} \mathrm{H}_{3} \mathrm{~N}\right]_{n}$, as a raw material has been highlighted for designing a sorbent because it is abundant—a high amount (i.e., > $>4$ million tons per year) has been discharged-and its stability in water is very advantages for the metal recovery process since metals or contaminants are mainly in aqueous phases. Other benefits of PAN fiber is its high strength, chemical resistivity, good mechanical properties, abrasion resistance, and electrostatic accumulation [17].

Because all fiber-form sorbents do not have good adsorption capacities, surface modification of fiber-formed sorbents are essential, as the case may be. In general, the technologies for functionalization of fiber can be divided into two categories: physical and chemical methods. The first case includes surface fibrillation and electric discharge, which can be used to change the structural and surface properties of the fiber and thus improve the mechanical bonding on the matrix. The latter can be conducted by hydrolysis, chemical coating, or activation [18].

In this study, we report the application of PAN fiber for a sorbent preparation for recovery of precious metals (i.e., $\mathrm{Pd}(\mathrm{II})$ or $\mathrm{Pt}(\mathrm{IV})$ ) from aqueous phases. The PAN fiber has cyanide groups, but the groups are not effective binding sites for the negatively charged metal ions [19]. Therefore, the surface of PAN fiber was physically and chemically modified by firstly spinning PAN-dimethylsulfoxide mixture in distilled water and secondly amidoximation to generate the binding sites on the surface for anionic metals. The adsorption capacity of the prepared sorbent was tested using single and binary metal systems to check its metal selectivity. Moreover, the adsorption capacity and selectivity were compared with those of commercially available and predominantly used ion-exchange resin (Amberjet ${ }^{\mathrm{TM}}$ 4200).

\section{Materials and Methods}

\subsection{Materials}

Hydroxylamine hydrochloride $\left(\mathrm{NH}_{2} \mathrm{OH} \cdot \mathrm{HCl}\right)$, Amberjet ${ }^{\mathrm{TM}} 4200$ ion-exchange resin, and polyacrylonitrile (PAN) with a molecular weight of 150,000 were all purchased from Sigma-Aldrich (Yongin, Korea). Sodium carbonate was obtained from Samchun Chemicals Co. (Seoul, Korea). Dimethylsulfoxide (DMSO) (99.5\%) was supplied by Daejung Chemicals Co., Ltd. (Siheung, Korea). Palladium(II) chloride $\left(\mathrm{PdCl}_{2}\right)$ and hydrogen hexachloroplatinate (IV) hydrate $\left(\mathrm{H}_{2} \mathrm{PtCl}_{6} \cdot 5.5 \mathrm{H}_{2} \mathrm{O}\right)$ as adsorbates were purchased from Kojima Chemicals Co., Ltd. (Sayama, Japan).

\subsection{Preparation of Polyacrylonitrile (PAN) Fiber}

To prepare $10 \%(w / v)$ PAN solution, $10 \mathrm{~g}$ of PAN was dissolved in $100 \mathrm{~mL}$ of DMSO by stirring for $24 \mathrm{~h}$ at $40 \pm 2{ }^{\circ} \mathrm{C}$. The PAN solution was poured into a $50 \mathrm{~mL}$ barrel with a needle tip with $0.14 \mathrm{~mm}$ diameter and was spun into distilled water at $0.25 \mathrm{MPa}$. Then, the PAN fiber was formed by a phase transition process in aqueous phase. The collected fiber was washed several times with distilled water to remove residual DMSO. The final product was stored in distilled water. 


\subsection{Chemical Modification of PAN Fiber}

To enhance the binding sites of the PAN fiber prepared in Section 2.2, it was chemically modified through the following processes. First, both $6 \mathrm{~g}$ of hydroxylamine hydrochloride and $4.5 \mathrm{~g}$ of sodium carbonate were mixed in $100 \mathrm{~mL}$ of distilled water at $70 \pm 2{ }^{\circ} \mathrm{C}$, and then, $3 \mathrm{~g}$ of wet PAN fiber was added to the mixture at $70 \pm 2{ }^{\circ} \mathrm{C}$ for different durations (5-30 min). After the chemical reaction, the activated PAN (called PAN-oxime fiber) was washed several times with distilled water, and then freeze-dried for $24 \mathrm{~h}$. The preparation methods are summarized in Scheme 1.

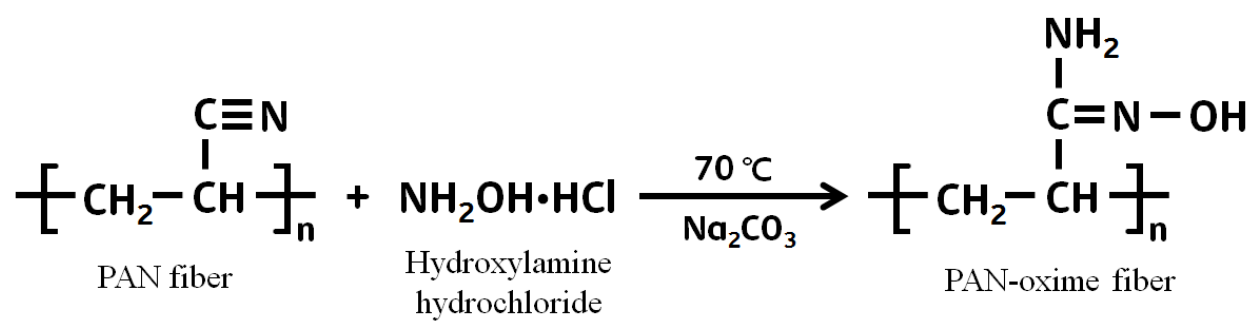

Scheme 1. Reaction for the synthesis of polyacrylonitrile (PAN)-oxime fiber.

\subsection{Characterization of PAN-Oxime Fiber}

To identify if the functionalization of the fibers in Section 2.3 was successfully performed, their infrared spectrum was analyzed using a Fourier-transform infrared spectrometer (FT-IR; Spectrum GX, Perkin Elmer, Waltham, MA, USA). The FT-IR samples were prepared as KBr discs and examined within the range of $4000-400 \mathrm{~cm}^{-1}$. Also, scanning electron microscopy (SEM; JSM-5900, JEOL, Tokyo, Japan) was used to observe the surface of the prepared sorbent.

\subsection{Batch Adsorption Experiments}

In order to evaluate the effect of the amidoximation time on adsorption capacity of a sorbent, a single-point adsorption experiment was conducted on $\mathrm{Pd}(\mathrm{II})$. Here, a Pd(II) solution of $1000 \mathrm{mg} / \mathrm{L}$ was prepared by adding $0.1 \mathrm{M} \mathrm{HCl}$ solution; then, $0.03 \mathrm{~g}$ of the fibrous adsorbents was added to $30 \mathrm{~mL}$ of $\mathrm{Pd}(\mathrm{II})$ solution in a $50 \mathrm{~mL}$ polypropylene conical tube. The tubes were continuously shaken by an incubator at $160 \mathrm{rpm}$ and $25 \pm 2{ }^{\circ} \mathrm{C}$ and their samples were carefully taken.

Isotherm experiments for testing sorption capacity and metal selectivity of the prepared and commercial sorbents were conducted. Here, also $0.03 \mathrm{~g}$ of PAN-oxime fiber or Amberjet ${ }^{\mathrm{TM}} 4200$ was added to $30 \mathrm{~mL}$ of metal solutions, which included $\mathrm{Pd}(\mathrm{II})$ and $\mathrm{Pt}(\mathrm{IV})$ single-metal systems or $\mathrm{Pd}(\mathrm{II})-\mathrm{Pt}(\mathrm{IV})$ binary metal systems for $24 \mathrm{~h}$ at $25 \pm 2{ }^{\circ} \mathrm{C}$. The stock solutions of metals were prepared in $0.1 \mathrm{M} \mathrm{HCl}$ solution and diluted if necessary. In these experiments, the initial concentrations were changed from 0 to approximately $1200 \mathrm{mg} / \mathrm{L}$.

The sorption kinetics of the adsorbents was performed to check equilibrium time. In this case, $0.1 \mathrm{~g}$ of the adsorbent was floated in $100 \mathrm{~mL}$ of $500 \mathrm{mg} / \mathrm{L}$ metal solution at $160 \mathrm{rpm}$ and $25 \pm 2{ }^{\circ} \mathrm{C}$. The kinetic samples were collected at fixed time intervals. All taken samples from supernatant of batches were analyzed using an inductively coupled plasma spectrometer (ICP; ICP-7510, Shimadzu, Kyoto, Japan).

For isotherm and kinetic experiments, five replicates of independent separate sorption experiments were conducted and the standard errors were within $5 \%$.

\section{Results and Discussion}

\subsection{The Effect on Amidoximation on the Preparation of PAN-Oxime Fiber}

The amine of amidoxime groups generated on the prepared sorbent (i.e., PAN-oxime fiber) by the chemical reaction can act as the binding sites for anionic metals via electrostatic interaction. Here, 
to check the effects of the reaction times, the morphological changes of the PAN fiber were examined at different reaction times, from 0 to $30 \mathrm{~min}$. As shown in Figure 1, the PAN fiber became a rigid form as the reaction time increased. The PAN-oxime fibers prepared within reaction times of 20-25 min were easily broken, and when the reaction time was $30 \mathrm{~min}$, the PAN-oxime fiber was agglomerated.
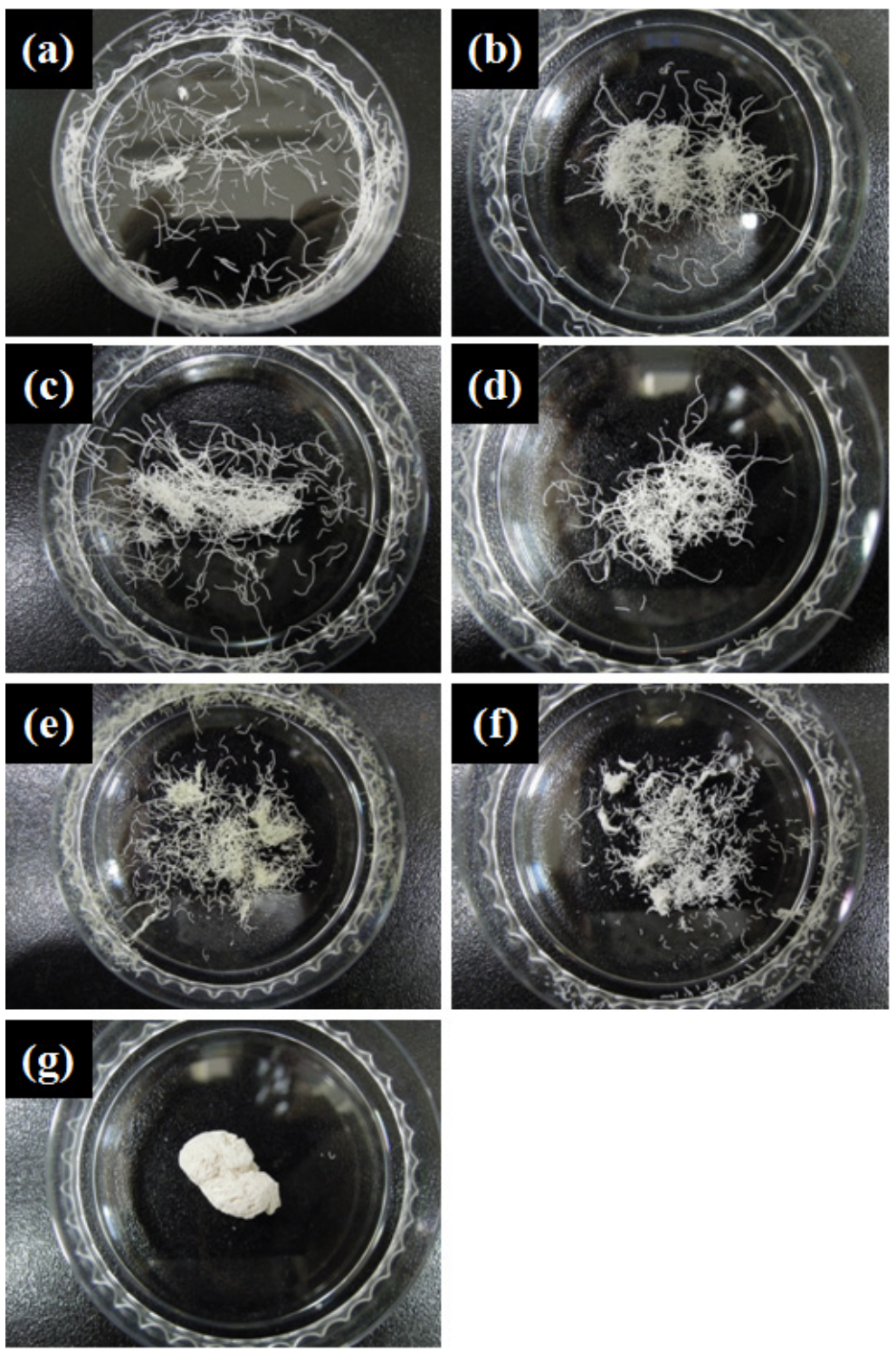

Figure 1. Photographs of the polyacrylonitrile (PAN)-oxime fibers prepared at different reaction times. (a) 0 min; (b) $5 \mathrm{~min}$; (c) $10 \mathrm{~min}$; (d) $15 \mathrm{~min}$; (e) $20 \mathrm{~min}$; (f) $25 \mathrm{~min}$; and (g) $30 \mathrm{~min}$.

In order to identify if the amidoximation was successfully carried out, an FT-IR study of raw PAN and the prepared sorbents at different reaction times (i.e., 15 and $30 \mathrm{~min}$ ) were performed. As shown in Figure 2, the FT-IR spectra of PAN and PAN-oxime fibers demonstrate several peaks of functional groups. The FT-IR spectrum of PAN fiber (Figure 2a) displays the most distinctive bonds of the nitrile groups $\left(\mathrm{C} \equiv \mathrm{N}\right.$ stretch; $\left.2246 \mathrm{~cm}^{-1}\right)$. After the chemical reaction of the matter, different spectral segments were observed (see Figure $2 b, c$ ). The FT-IR spectra of PAN-oxime fibers showed that the intensity of the nitrile peak $\left(2246 \mathrm{~cm}^{-1}\right)$ decreased as the reaction time increased, and instead the characteristic peaks of the functional groups appeared at around $1669,1621,1380,923$, and $3800-3000 \mathrm{~cm}^{-1}$. These peaks result from the $\mathrm{C}=\mathrm{N}$ stretch, $\mathrm{N}-\mathrm{H}$ bend, $\mathrm{C}-\mathrm{N}$ stretch, $\mathrm{N}-\mathrm{H}$ bond, and overlapping of the $\mathrm{O}-\mathrm{H}$ and $\mathrm{N}-\mathrm{H}$ stretch, respectively. Therefore, it was confirmed that the chemical reaction was appropriately 
performed to generate functional groups for anionic metals. However, the microscopic analysis did not show significant difference between PAN and PAN-oxime fiber, as shown in Figure 3. This indicates that the chemical modification was generated on the surface of the PAN fiber, while physical structure of the PAN fiber was not affected by the chemical reaction. Thus, the diameters of the adsorbents produced at different reaction times were similar $(\sim 100 \mu \mathrm{m})$. However, in the case of reaction for $30 \mathrm{~min}$, the fiber could not maintain its shape, but aggregated likely due to the extensive extent of reaction.

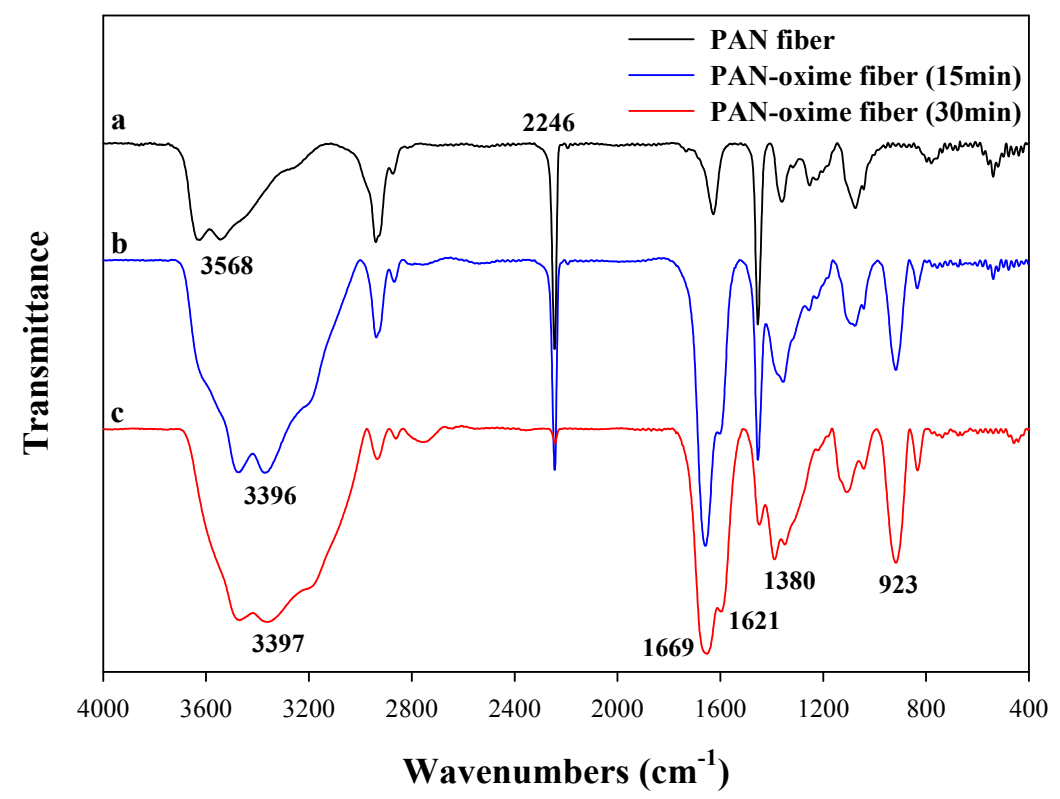

Figure 2. Fourier-transform infrared (FT-IR) spectra of PAN fiber and PAN-oxime fiber at different reaction times: (a) $0 \mathrm{~min}$; (b) $15 \mathrm{~min}$; and (c) $30 \mathrm{~min}$.
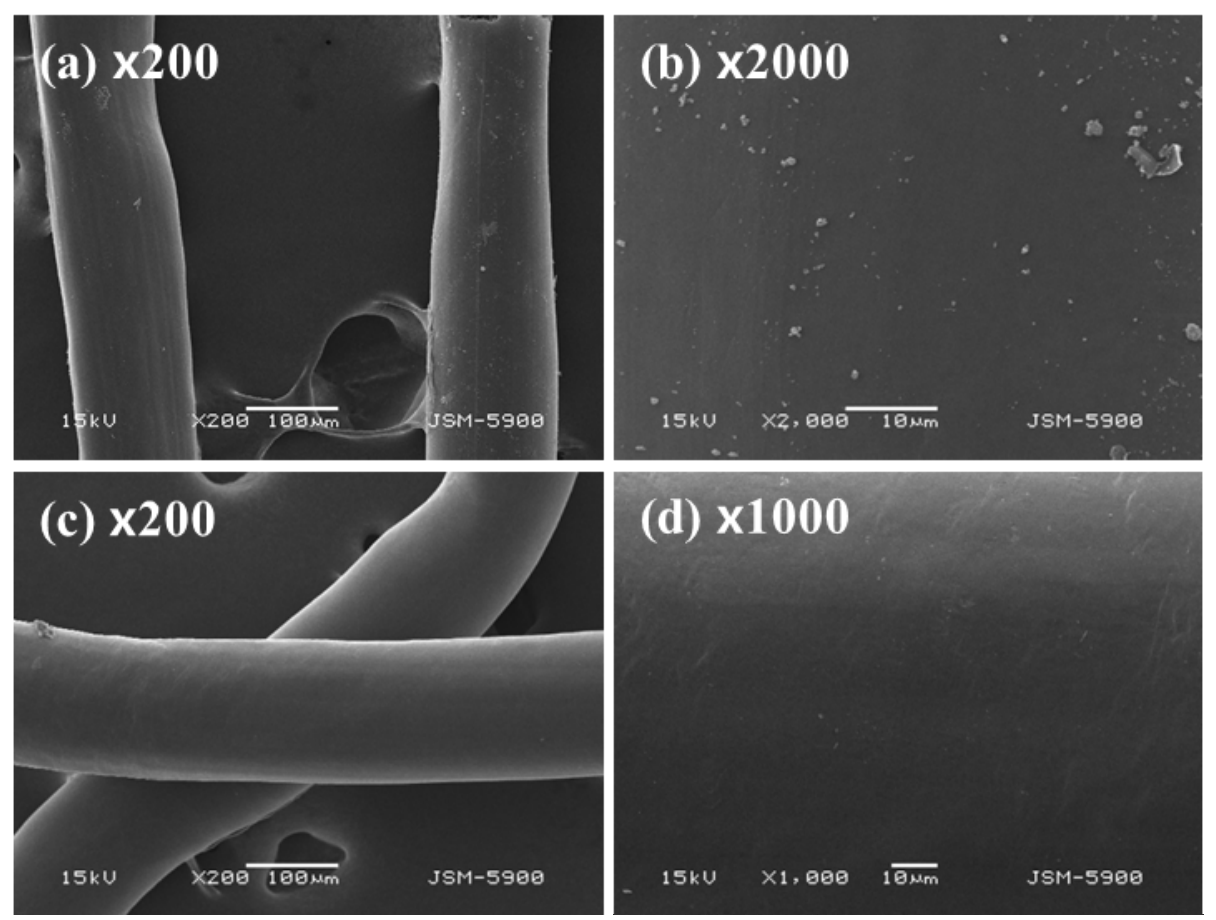

Figure 3. Scanning electron microscopy (SEM) images of (a) PAN fiber $\times 200$ magnification; (b) PAN fiber $\times 2000$ magnification; (c) PAN-oxime fiber $\times 200$ magnification; and (d) PAN-oxime fiber $\times 1000$ magnification. The PAN-oxime fiber was prepared with a reaction time of $15 \mathrm{~min}$. 


\subsection{Effect of Amidoximation Time on Adsorption Capacity}

The effect of amidoximation time on the adsorption capacity of $\mathrm{Pd}(\mathrm{II})$ was studied. For that, the PAN-oxime fibers were prepared at different reaction times, from 0 to $30 \mathrm{~min}$ at $5 \mathrm{~min}$ intervals. Here, the PAN-oxime fiber reacted for $30 \mathrm{~min}$ was excluded because it was agglomerated and fiber no longer formed. After the adsorption experiments, the amount of adsorbed Pd(II) ions per unit mass of adsorbent $\left(q_{\mathrm{t}}, \mathrm{mg} / \mathrm{g}\right)$ was calculated by a mass balance equation [20].

$$
q_{\mathrm{t}}=\left(V_{0} C_{0}-V_{\mathrm{f}} C_{\mathrm{f}}\right) / M
$$

where $V_{0}$ and $V_{\mathrm{f}}$ are the initial and final solution volumes $(\mathrm{L})$, respectively, $C_{0}$ and $C_{\mathrm{f}}$ are the initial and final solution concentrations of metal ions ( $\mathrm{mg} / \mathrm{L})$, respectively, and $M$ is the mass of adsorbent $(\mathrm{g})$.

As shown in Figure 4, it was checked that the PAN-oxime fiber could be used for the recovery of precious metals, and the $\mathrm{Pd}(\mathrm{II})$ uptake increased as the reaction time increased. This means that the longer reaction time, the more binding sites that were generated. When the PAN-oxime fiber reacted for $25 \mathrm{~min}$ was used, the highest $(412.6 \mathrm{mg} / \mathrm{g}$ ) Pd(II) uptake was observed, while raw PAN fiber (reaction time $=0$ ) has no metal adsorption, but shows a negative value due to water evaporation in this sample. However, for further studies (i.e., isotherm and kinetics), the PAN-oxime fiber reacted for $15 \mathrm{~min}$ was chosen because the fiber produced from $20 \mathrm{~min}$ reaction was too weak and brittle to be used.

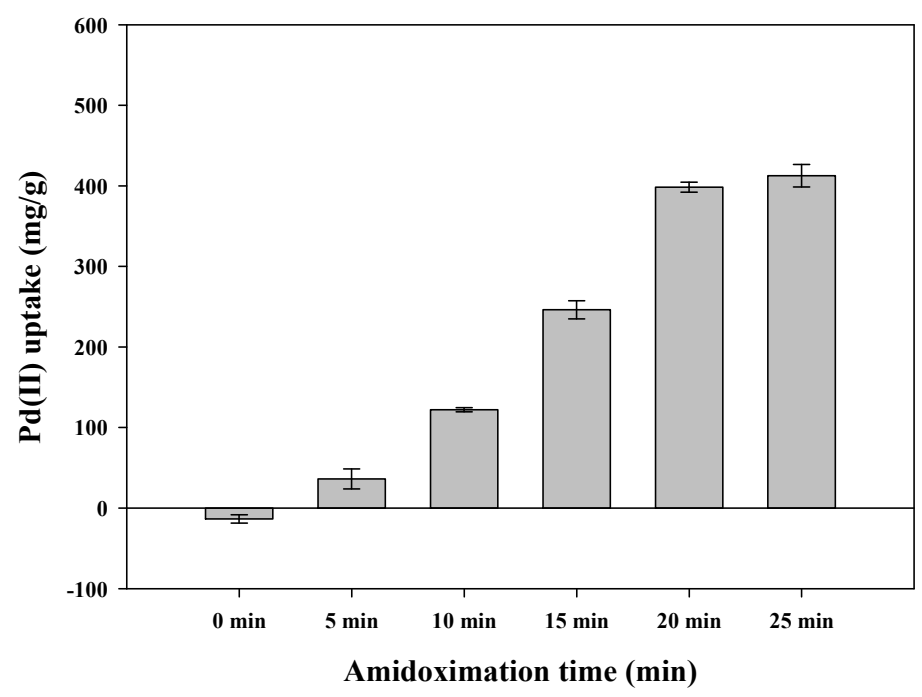

Figure 4. Effect of amidoximation time on the $\mathrm{Pd}(\mathrm{II})$ uptake by PAN-oxime fiber.

\subsection{Isotherms Study}

The isotherm studies using the PAN-oxime fiber developed with a 15 min reaction time were conducted in single and binary metal systems of $\mathrm{Pd}(\mathrm{II})$ and $\mathrm{Pt}(\mathrm{IV})$. The adsorption capacities were compared with those of commercial ion-exchange resin (Amberjet ${ }^{\mathrm{TM}} 4200$ ) which is predominantly used for metal adsorption. In order to evaluate the maximum adsorption capacity from the experimental data, the Langmuir isotherm model [21] was applied. The nonlinear Langmuir equation is shown below:

$$
\text { Langmuir model : } q_{\mathrm{e}}=q_{\mathrm{m}} b C_{\mathrm{e}} /\left(1+b C_{\mathrm{e}}\right)
$$

where $q_{\mathrm{e}}$ is the uptake of metal at equilibrium $(\mathrm{mg} / \mathrm{g})$ and $C_{\mathrm{e}}$ is the concentration of the metal solution at equilibrium $(\mathrm{mg} / \mathrm{L}) \cdot q_{\mathrm{m}}$ and $b$ are related to the Langmuir constant, and they represent the adsorption capacity $(\mathrm{mg} / \mathrm{g})$ and affinity $(\mathrm{L} / \mathrm{mg})$, respectively. 
As shown in Figure 5a, adsorption capacities for Pd(II) and Pt(IV) of both PAN-oxime fiber and Amberjet ${ }^{\mathrm{TM}} 4200$ increase in the single-metal systems as the equilibrium concentrations of respective metals increase. The estimated parameters are given in Table 1. In single-metal systems, the maximum uptakes of $\mathrm{Pd}(\mathrm{II})$ and $\mathrm{Pt}(\mathrm{IV})$ by PAN-oxime fiber were estimated to be $244.06 \pm 10.68$ and $175.65 \pm 6.62 \mathrm{mg} / \mathrm{g}$, respectively. Those of Pd(II) and Pt(IV) by Amberjet ${ }^{\mathrm{TM}} 4200$ were estimated $^{2}$ to be $310.05 \pm 13.25$ and $422.65 \pm 21.33 \mathrm{mg} / \mathrm{g}$, respectively. In general, the sorption capacities of Amberjet ${ }^{\mathrm{TM}} 4200$ for $\mathrm{Pd}(\mathrm{II})$ and $\mathrm{Pt}(\mathrm{IV})$ were higher than those of the PAN-oxime fiber.

Table 1. Langmuir parameters in single and binary metal systems.

\begin{tabular}{|c|c|c|c|c|c|}
\hline \multirow{2}{*}{ Adsorbents } & \multirow{2}{*}{ Conditions } & \multirow{2}{*}{ Metals } & \multicolumn{3}{|c|}{ Parameters } \\
\hline & & & $q_{\mathrm{m}}(\mathrm{mg} / \mathrm{g})$ & $b$ (L/mg) & $\mathbf{R}^{2}$ \\
\hline \multirow{4}{*}{ PAN-oxime fiber } & \multirow{2}{*}{ Single } & $\mathrm{Pd}(\mathrm{II})$ & $244.06 \pm 10.68$ & $0.435 \pm 0.138$ & 0.928 \\
\hline & & $\mathrm{Pt}(\mathrm{IV})$ & $175.64 \pm 6.62$ & $0.052 \pm 0.012$ & 0.960 \\
\hline & \multirow{2}{*}{ Binary } & $\mathrm{Pd}(\mathrm{II})$ & $234.54 \pm 11.53$ & $0.589 \pm 0.214$ & 0.905 \\
\hline & & $\mathrm{Pt}(\mathrm{IV})$ & - & - & - \\
\hline \multirow{4}{*}{ Amberjet $^{\mathrm{TM}} 4200$} & \multirow{2}{*}{ Single } & $\mathrm{Pd}(\mathrm{II})$ & $310.05 \pm 13.25$ & $0.107 \pm 0.026$ & 0.964 \\
\hline & & $\mathrm{Pt}(\mathrm{IV})$ & $422.65 \pm 21.33$ & $0.239 \pm 0.053$ & 0.955 \\
\hline & \multirow{2}{*}{ Binary } & $\mathrm{Pd}(\mathrm{II})$ & $163.35 \pm 6.09$ & $0.340 \pm 0.093$ & 0.955 \\
\hline & & $\mathrm{Pt}(\mathrm{IV})$ & $198.61 \pm 6.64$ & $0.473 \pm 0.116$ & 0.966 \\
\hline
\end{tabular}

In the binary metal system, the adsorption behaviors of the PAN-oxime fiber were quite interesting compared to those of Amberjet ${ }^{\mathrm{TM}}$ 4200. In case of Amberjet ${ }^{\mathrm{TM}}$ 4200, its metal uptakes in the binary metal mixture were lower than those in the single-metal systems, and it did not show any metal selectivity (Figure 5). However, in the same condition, $\mathrm{Pd}(\mathrm{II})$ uptakes of PAN-oxime fiber were similar in both cases of single $(244.06 \pm 10.68 \mathrm{mg} / \mathrm{g})$ and binary metal systems $(234.54 \pm 11.53 \mathrm{mg} / \mathrm{g})$. Note that the maximum $\mathrm{Pd}(\mathrm{II})$ uptake of PAN-oxime in the binary metal system may be higher than the calculated value, since the isotherm of $\mathrm{Pt}(\mathrm{IV})$ could not be fitted by the Langmuir model. Surprisingly, $\mathrm{Pt}(\mathrm{IV})$ uptake of PAN-oxime fiber, in the case of the multi-metal system, was significantly lowered (Figure $5 \mathrm{~b}$ ) from $62.99 \mathrm{mg} / \mathrm{g}$ in a single-metal system to $39.62 \mathrm{mg} / \mathrm{L}$ in a binary metal system. This indicates that PAN-oxime fiber has selective binding ability for $\mathrm{Pd}(\mathrm{II})$ in a mixture of $\mathrm{Pd}(\mathrm{II})$ and $\mathrm{Pt}(\mathrm{IV})$. For better comparison, the selectivity coefficients $\left(\alpha_{P d(I I) / P t(I V)}\right)$ of PAN-oxime and Amberjet ${ }^{\mathrm{TM}}$ 4200 for $\mathrm{Pd}(\mathrm{II})$ in the mixture of $\mathrm{Pd}(\mathrm{II})$ and $\mathrm{Pt}(\mathrm{IV})$ were calculated using Equation (3).

$$
\alpha_{P d(I I) / P t(I V)}=\frac{q_{t, P d(I I)} / C_{f, P d(I I)}}{q_{t, P t(I V)} / C_{f, P t(I V)}}
$$

where $q_{t, P d(I I)}$ and $q_{t, P t(I V)}$ are the uptakes of $\mathrm{Pd}(\mathrm{II})$ and $\mathrm{Pt}(\mathrm{IV})$, respectively, and $C_{f, P d(I I)}$ and $C_{f, P t(I V)}$ are the final concentrations of $\mathrm{Pd}(\mathrm{II})$ and $\mathrm{Pt}(\mathrm{IV})$, respectively. Based on Equation (3), the selectivity coefficients of PAN-oxime and Amberjet ${ }^{\mathrm{TM}} 4200$ at the initial metal concentrations (200 1000 mg/L) could be calculated. As can be seen in Figure 5 c, the selectivity coefficients toward Pd(II) of PAN-oxime ranged from 15 to 33, which was approximately 19 89 times higher than those of Amberjet ${ }^{\mathrm{TM}} 4200$. The selectivity of PAN-oxime decreased when initial metal concentration increased. 


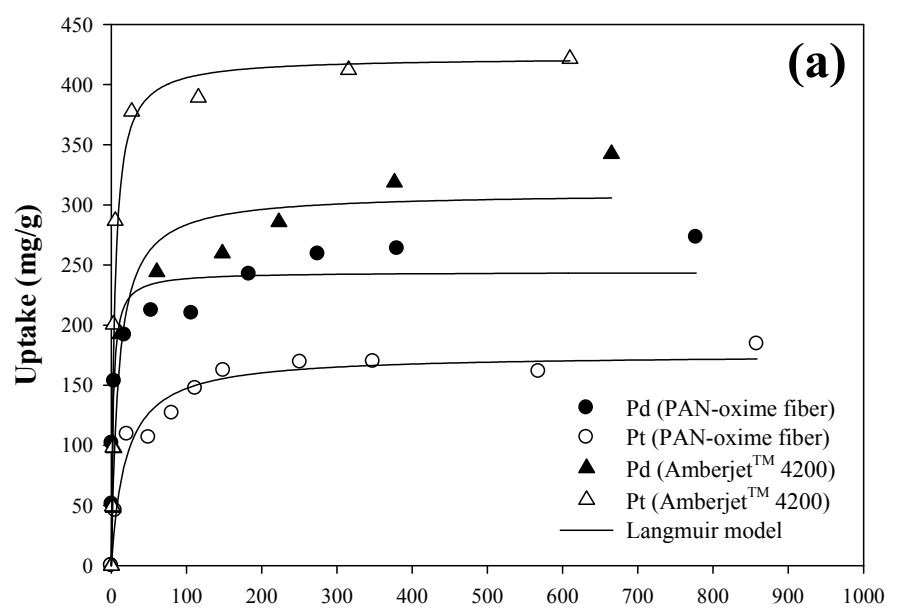

Equilibrium metal concentration (mg/L)

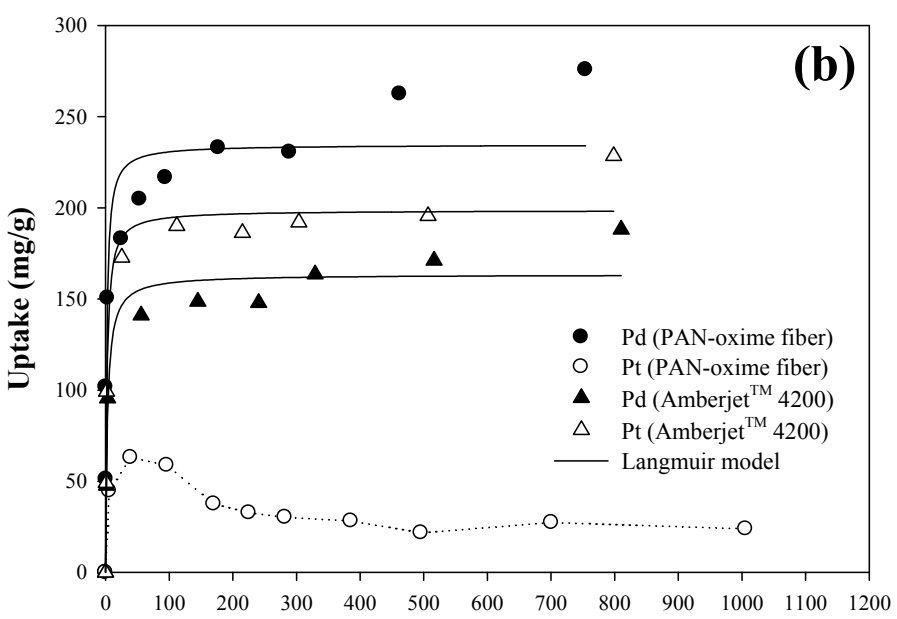

Equilibrium metal concentration $(\mathrm{mg} / \mathrm{L})$

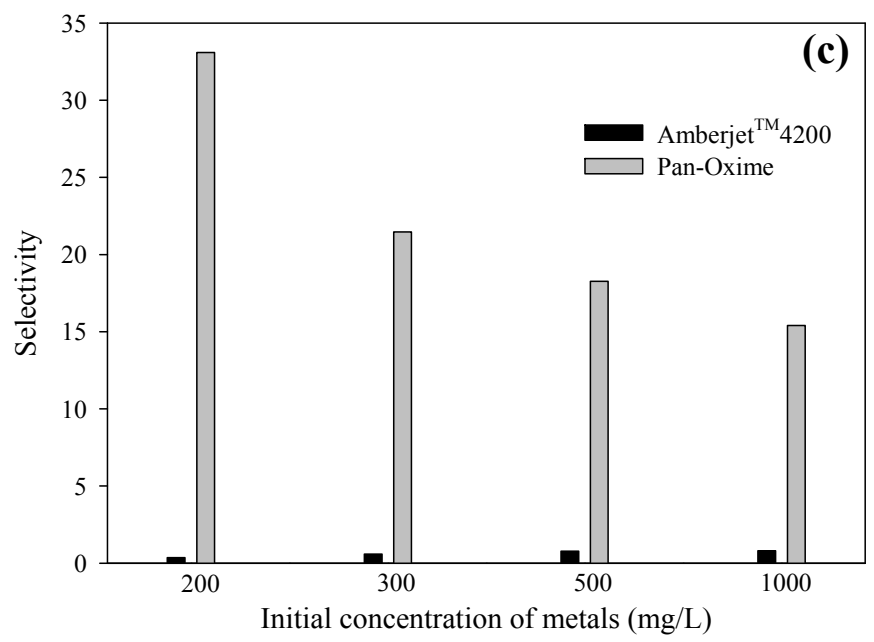

Figure 5. Adsorption isotherms of PAN-oxime fiber and Amberjet ${ }^{\mathrm{TM}}$ 4200. (a) Single-metal system; (b) binary metal system; and (c) selectivity. Standard errors are less than $5 \%$.

\subsection{Kinetic Study}

Figure $6 \mathrm{a}, \mathrm{b}$ shows the kinetics of the developed PAN-oxime fiber in single and binary metal systems, respectively, and Figure 6c shows the kinetic results of the Amberjet ${ }^{\mathrm{TM}} 4200$ resin in the binary metal system. As a result, more than $90 \%$ of the adsorptions by PAN-oxime fiber were 
completed within 10 min, while Amberjet ${ }^{\mathrm{TM}} 4200$ was done within 120 min of contact with the metal solution. This indicates that PAN-oxime fiber has much better sorption kinetics than Amberjet ${ }^{\mathrm{TM}} 4200$, because the former supports plenty of binding sites as a thin fiber form. In order to evaluate the kinetic results, the data points were fitted by pseudo-first- and pseudo-second-order models, which can be represented by their nonlinear kinetic equations as follows [22]:

$$
\begin{aligned}
& \text { Pseudo-first-order model : } q_{\mathrm{t}}=q_{1}\left(1-\exp \left(-k_{1} t\right)\right) \\
& \text { Pseudo-second-order model : } q_{\mathrm{t}}=q_{2}^{2} k_{2} t /\left(1+q_{2} k_{2} t\right)
\end{aligned}
$$

where both $q_{1}$ and $q_{2}$ are the amount of adsorbed metal ions at equilibrium $(\mathrm{mg} / \mathrm{g}), q_{\mathrm{t}}$ is the amount of adsorbed metal ions at any time $t(\mathrm{mg} / \mathrm{g}), k_{1}$ is the rate constant in the pseudo-first-order model $\left(\mathrm{min}^{-1}\right)$, and $k_{2}$ is the rate constant in the pseudo-second-order model $(\mathrm{g} / \mathrm{mg} \cdot \mathrm{min})$. The experimental and predicted equilibrium uptakes, rate constants, and correlation coefficients are exhibited in Table 2.
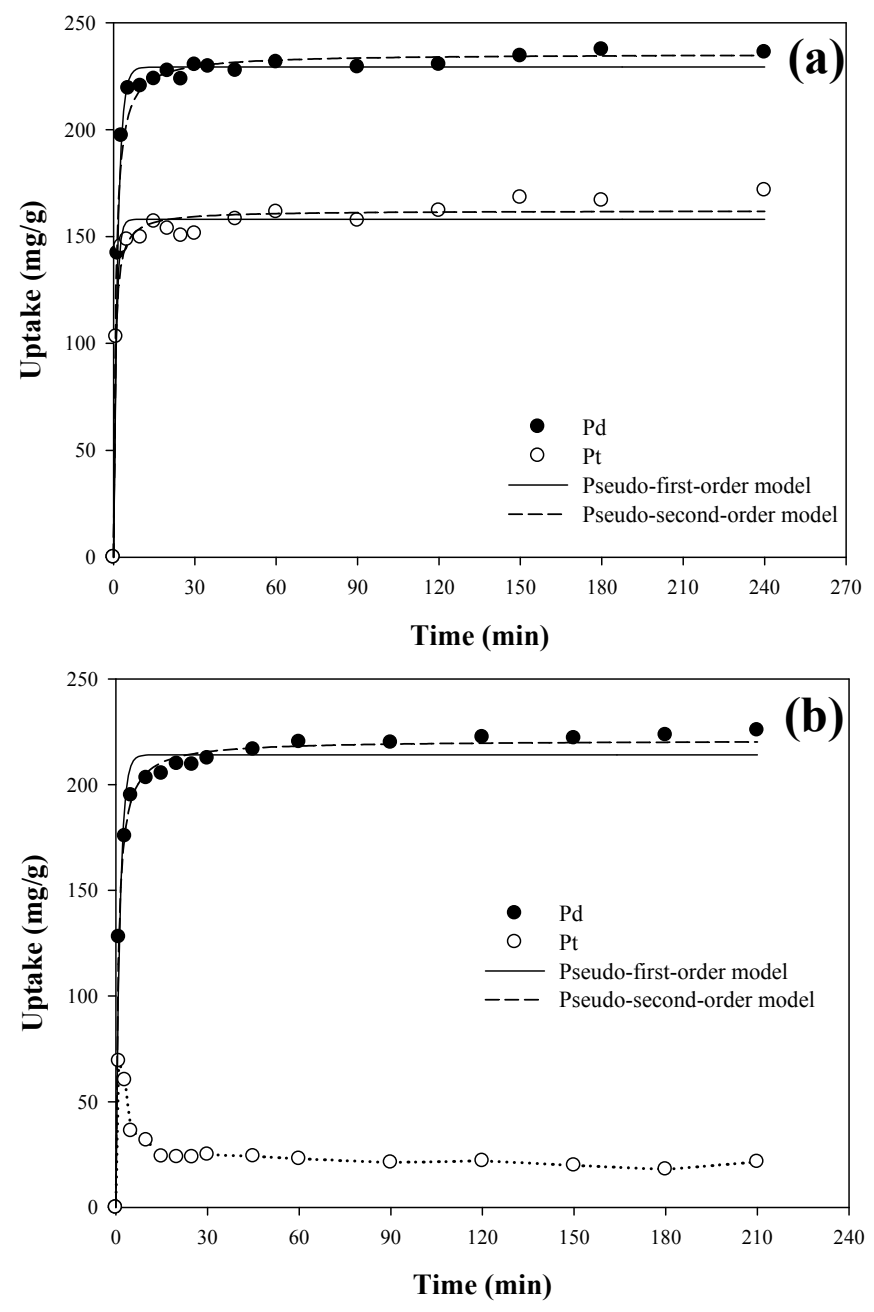

Figure 6. Cont. 


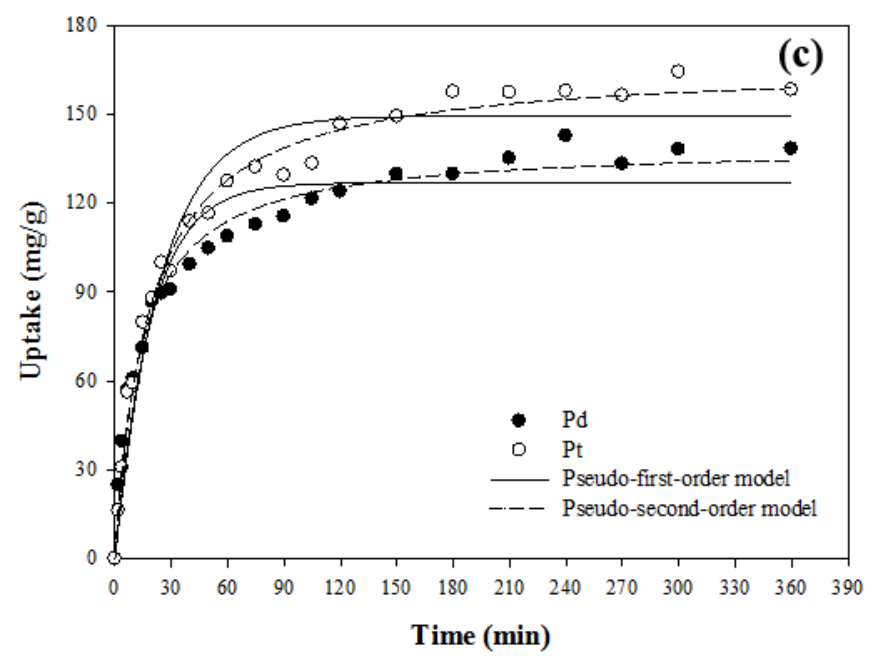

Figure 6. Adsorption kinetics of PAN-oxime fiber in single-metal system (a) and binary metal system (b); and of Amberjet ${ }^{\mathrm{TM}} 4200$ in binary metal system (c). Standard errors are less than 5\%.

Table 2. Kinetic parameters of the pseudo-first-order and pseudo-second-order models.

\begin{tabular}{|c|c|c|c|c|c|c|c|c|}
\hline \multirow[b]{2}{*}{ Adsorbents } & \multirow[b]{2}{*}{ Conditions } & \multirow[b]{2}{*}{ Metals } & \multicolumn{3}{|c|}{ Pseudo-First-Order } & \multicolumn{3}{|c|}{ Pseudo-Second-Order } \\
\hline & & & $q_{1}(\mathrm{mg} / \mathrm{g})$ & $k_{1}\left(\min ^{-1}\right)$ & $\mathbf{R}^{2}$ & $q_{2}(\mathrm{mg} / \mathrm{g})$ & $\begin{array}{c}k_{2} \times 10^{-3} \\
(\mathrm{~g} / \mathrm{mg} \cdot \mathrm{min})\end{array}$ & $\mathbf{R}^{2}$ \\
\hline \multirow{4}{*}{ PAN-oxime fiber } & \multirow{2}{*}{ Single } & $\operatorname{Pd}(\mathrm{II})$ & $229.26 \pm 1.22$ & $0.644 \pm 0.028$ & 0.994 & $235.52 \pm 1.86$ & $5.5 \pm 0.5$ & 0.990 \\
\hline & & $\mathrm{Pt}(\mathrm{IV})$ & $158.04 \pm 1.93$ & $1.008 \pm 0.117$ & 0.973 & $162.16 \pm 1.72$ & $11.5 \pm 1.7$ & 0.983 \\
\hline & \multirow{2}{*}{ Binary } & $\operatorname{Pd}(\mathrm{II})$ & $214.09 \pm 2.74$ & $0.757 \pm 0.084$ & 0.972 & $221.00 \pm 1.05$ & $6.0 \pm 0.3$ & 0.997 \\
\hline & & $\mathrm{Pt}(\mathrm{IV})$ & - & - & - & - & - & - \\
\hline \multirow{2}{*}{ Amberjet ${ }^{\mathrm{TM}} 4200$} & \multirow{2}{*}{ Binary } & $\mathrm{Pd}(\mathrm{II})$ & $126.84 \pm 3.10$ & $0.053 \pm 0.006$ & 0.933 & $139.48 \pm 2.11$ & $0.5 \pm 0.04$ & 0.984 \\
\hline & & $\mathrm{Pt}(\mathrm{IV})$ & $149.40 \pm 3.22$ & $0.041 \pm 0.004$ & 0.959 & $166.82 \pm 2.19$ & $0.3 \pm 0.02$ & 0.991 \\
\hline
\end{tabular}

"-" represents that the data cannot be estimated using the pseudo-first- and pseudo-second-order models.

As shown in Figure 6a, high amounts of $\mathrm{Pd}(\mathrm{IV})$ and $\mathrm{Pt}(\mathrm{II})$ were rapidly adsorbed onto the PAN-oxime fiber in single-metal conditions, whose final uptakes were 235.52 and $162.16 \mathrm{mg} / \mathrm{g}$, respectively. In the binary metal systems, the final uptake of $\mathrm{Pd}(\mathrm{II})$ by the PAN-oxime fiber was $221.00 \mathrm{mg} / \mathrm{g}$, but the Pt(IV) uptake could not be estimated by the pseudo-second-order because an unusual phenomenon of $\mathrm{Pt}(\mathrm{IV})$ adsorption by PAN-oxime fiber was observed (Figure $6 \mathrm{~b}$ ). If it was visually checked, it was around $20 \sim 25 \mathrm{mg} / \mathrm{g}$ after $30 \mathrm{~min}$. Again, in the beginning, Pt(IV) was adsorbed together with $\mathrm{Pd}(\mathrm{II})$ onto PAN-oxime fiber. However, as the $\mathrm{Pd}(\mathrm{II})$ uptake increased, the uptake of $\mathrm{Pt}(\mathrm{IV})$ sharply declined, which shows that initially adsorbed $\mathrm{Pt}(\mathrm{IV})$ was desorbed in a few minutes. This implies that $\mathrm{Pd}(\mathrm{II})$ has stronger binding affinity with the sorbent than $\mathrm{Pt}(\mathrm{IV})$. Although the commercial resin Amberjet ${ }^{\mathrm{TM}} 4200$ has higher sorption capacities for both metal ions than PAN-oxime fiber in the single-metal system, it does not have the selective binding property in the binary system. However, the developed PAN-oxime fiber shows selectivity toward Pd(II) in the binary system. In addition, PAN-oxime fiber can bind metal ions much more quickly than the resin.

\section{Conclusions}

Polyacrylonitrile (PAN) fiber has been abundantly discharged from industrial textile factories, thus its recycling studies are essential. In this study, we applied PAN for preparing an excellent adsorbent for a fast and selective recovery process for precious metals (i.e., $\mathrm{Pd}(\mathrm{II})$ and $\mathrm{Pt}(\mathrm{IV})$ ). For sorbent preparation with appropriate functional groups for metal binding (PAN-oxime fiber), spinning a PAN-dimethylsulfoxide mixture in water, followed by amidoxime chemical modification, was carried out. For the surface modification, it was found that as amidoximation time increased, the conversion from PAN to PAN-oxime increased. However, reaction greater than $20 \mathrm{~min}$ led to 
destruction of the fibrous structure. Isotherm and kinetic experiments in the single-metal systems showed that the uptakes of Pd(II) and Pt(IV) by Amberjet ${ }^{\mathrm{TM}} 4200$ were approximately 1.3 and 2.4 times higher than those by the PAN-oxime fiber, respectively. However, in the binary solution, PAN-oxime fiber showed high selectivity for $\mathrm{Pd}(\mathrm{II})$, and moreover it had a much faster equilibrium time than Amberjet ${ }^{\mathrm{TM}} 4200$.

This study showed that the PAN textile can be used to prepare an excellent adsorbent. As an example, it was clearly shown that the developed PAN-oxime fiber shows great potential for recovering anionic metals. Moreover, since it has fast binding ability and selectivity, it can be applied in column systems and other separation processes.

Acknowledgments: This work was supported by the Korean Government through KETEP (20115020100060) and KEITI (The Eco-Innovation project 20115020100060 ) grants and the Korean Government through NRF grant (2014R1A1A2008337 and 2014R1A2A1A09007378).

Author Contributions: Areum Lim and Myung-Hee Song contributed to sorbent development, batch experiments, and FTIR \& microscopic analyses under supervision of Chul-Woong Cho and Yeoung-Sang Yun.

Conflicts of Interest: The authors declare no conflict of interest.

\section{References}

1. Ravindra, K.; Bencs, L.; Van Grieken, R. Platinum group elements in the environment and their health risk. Sci. Total Environ. 2004, 318, 1-43. [CrossRef]

2. Demopoulos, G.P. Solvent extraction in precious metals refining. JOM 1986, 38, 13-17. [CrossRef]

3. Lee, J.Y.; Raju, B.; Kumar, B.N.; Kumar, J.R.; Park, H.K.; Reddy, B.R. Solvent extraction separation and recovery of palladium and platinum from chloride leach liquors of spent automobile catalyst. Sep. Purif. Technol. 2010, 73, 213-218. [CrossRef]

4. Golunski, S.; Rajaram, R.; Hodge, N.; Hutchings, G.J.; Kiely, C.J. Low-temperature redox activity in co-precipitated catalysts: A comparison between gold and platinum-group metals. Catal. Today 2002, 72, 107-113. [CrossRef]

5. Schreier, G.; Edtmaier, C. Separation of Ir, Pd and Rh from secondary Pt scrap by precipitation and calcination. Hydrometallurgy 2003, 68, 69-75. [CrossRef]

6. Dabrowski, A.; Hubicki, Z.; Podkościelny, P.; Robens, E. Selective removal of the heavy metal ions from waters and industrial wastewaters by ion-exchange method. Chemosphere 2004, 56, 91-106. [CrossRef] [PubMed]

7. Gaita, R.; Al-Bazi, S.J. An ion-exchange method for selective separation of palladium, platinum and rhodium from solutions obtained by leaching automotive catalytic converters. Talanta 1995, 42, 249-255. [CrossRef]

8. Birinci, E.; Gülfen, M.; Aydın, A.O. Separation and recovery of palladium(II) from base metal ions by melamine-formaldehyde-thiourea (MFT) chelating resin. Hydrometallurgy 2009, 95, 15-21. [CrossRef]

9. Mack, C.; Wilhelmi, B.; Duncan, J.R.; Burgess, J.E. Biosorption of precious metals. Biotechnol. Adv. 2007, 25, 264-271. [CrossRef] [PubMed]

10. Koduru, J.R.; Lee, K.D. Separation studies of Pd(II) from acidic chloride solutions of Pt(IV), Ni(II) and Rh(III) by using 4-aroyl-3-phenyl-5-isoxazolones. J. Chem. 2012, 9, 756-765.

11. Coşkun, R.; Soykan, C. Preparation of amidoximated polyester fiber and competitive adsorption of some heavy metal ions from aqueous solution onto this fiber. J. Appl. Polym. Sci. 2009, 112, 1798-1807. [CrossRef]

12. Lin, W.; Hsieh, Y.-L. Kinetics of metal ion absorption on ion-exchange and chelating fibers. Ind. Eng. Chem. Res. 1996, 35, 3817-3821. [CrossRef]

13. Yan, W.; Watson, V.J.; Logan, B.E. Substantial humic acid adsorption to activated carbon air cathodes produces a small reduction in catalytic activity. Environ. Sci. Technol. 2016, 50, 8904-8909.

14. Deng, H.; Ning, J.; Wang, X. Amino-functionalized cotton fiber for enhanced adsorption of active brilliant red X-38 from aqueous solution. Microsc. Res. Tech. 2016. [CrossRef] [PubMed]

15. Rivera, L.O.; Bakaev, V.A.; Banerjee, J.; Mueller, K.T.; Pantano, C.G. Characterization and reactivity of sodium aluminoborosilicate glass fiber surfaces. Appl. Surf. Sci. 2016, 370, 328-334. [CrossRef] 
16. Oyloa, Y.; Dai, S. High surface-area amidoxime-based polymer fibers co-grafted with various acid monomers yielding increased adsorption capacity for the extraction of uranium from weawater. Dalton Trans. 2016, 45, 8824-8834. [CrossRef] [PubMed]

17. Nam, C.-W.; Kim, Y.-H.; Ko, S.-W. Modification of polyacrylonitrile (PAN) fiber by blending with N-(2-hydroxy)propyl-3-trimethyl-ammonium chitosan chloride. J. Appl. Polym. Sci. 1999, 74, 2258-2265. [CrossRef]

18. George, J.; Sreekala, M.S.; Thomas, S. A review on interface modification and characterization of natural fiber reinforced plastic composites. Polym. Eng. Sci. 2001, 41, 1471-1485. [CrossRef]

19. Saeed, K.; Haider, S.; Oh, T.-J.; Park, S.-Y. Preparation of amidoxime-modified polyacrylonitrile (PAN-oxime) nanofibers and their applications to metal ions adsorption. J. Membr. Sci. 2008, 322, 400-405. [CrossRef]

20. Vijayaraghavan, K.; Yun, Y.-S. Bacterial biosorbents and biosorption. Biotechnol. Adv. 2008, 26, $266-291$. [CrossRef] [PubMed]

21. Langmuir, I. The adsorption of gases on plane surfaces of glass, mica and platinum. J. Am. Chem. Soc. 1918, 40, 1361-1403. [CrossRef]

22. Chiou, M.-S.; Li, H.-Y. Equilibrium and kinetic modeling of adsorption of reactive dye on cross-linked chitosan beads. J. Hazard. Mater. 2002, 93, 233-248. [CrossRef]

(C) 2016 by the authors; licensee MDPI, Basel, Switzerland. This article is an open access article distributed under the terms and conditions of the Creative Commons Attribution (CC-BY) license (http://creativecommons.org/licenses/by/4.0/). 